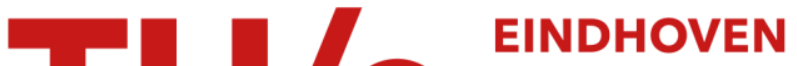 UNIVERSITY OF TECHNOLOGY
}

\section{Bubble point pressures of binary system of methanol and methyl propionate}

Citation for published version (APA):

Shariati, A., Florusse, L. J., Kroon, M. C., \& Peters, C. J. (2016). Bubble point pressures of binary system of methanol and methyl propionate. Fluid Phase Equilibria, 417, 166-170.

https://doi.org/10.1016/j.fluid.2016.02.036

DOI:

10.1016/j.fluid.2016.02.036

Document status and date:

Published: 15/06/2016

Document Version:

Accepted manuscript including changes made at the peer-review stage

Please check the document version of this publication:

- A submitted manuscript is the version of the article upon submission and before peer-review. There can be important differences between the submitted version and the official published version of record. People interested in the research are advised to contact the author for the final version of the publication, or visit the $\mathrm{DOI}$ to the publisher's website.

- The final author version and the galley proof are versions of the publication after peer review.

- The final published version features the final layout of the paper including the volume, issue and page numbers.

Link to publication

\section{General rights}

Copyright and moral rights for the publications made accessible in the public portal are retained by the authors and/or other copyright owners and it is a condition of accessing publications that users recognise and abide by the legal requirements associated with these rights.

- Users may download and print one copy of any publication from the public portal for the purpose of private study or research.

- You may not further distribute the material or use it for any profit-making activity or commercial gain

- You may freely distribute the URL identifying the publication in the public portal.

If the publication is distributed under the terms of Article $25 \mathrm{fa}$ of the Dutch Copyright Act, indicated by the "Taverne" license above, please follow below link for the End User Agreement:

www.tue.nl/taverne

Take down policy

If you believe that this document breaches copyright please contact us at:

openaccess@tue.nl

providing details and we will investigate your claim. 
Bubble point pressures of binary system of methanol and methyl propionate

\begin{abstract}
Alireza Shariati $^{1, *}$, Louw J. Florusse ${ }^{2}$, M.C. Kroon ${ }^{3}$, Cor J. Peters ${ }^{3,4}$
${ }^{1}$ Natural Gas Engineering Department, School of Chemical and Petroleum Engineering, Shiraz University, Molla Sadra Avenue, Shiraz 71345, Iran

${ }^{2}$ DelftChemTech, Delft University of Technology, Julianalaan 136, 2628 BL Delft, The Netherlands
\end{abstract}

${ }^{3}$ Separation Technology Group, Department of Chemical Engineering and Chemistry, Eindhoven University of Technology, Den Dolech 2, 5612 AZ Eindhoven, The Netherlands

${ }^{4}$ Chemical Engineering Department, The Petroleum Institute, P.O. Box 2533, Abu Dhabi, United Arab Emirates

\footnotetext{
*Corresponding author. E-mail: shariati@shirazu.ac.ir
} 


\section{Abstract}

In this work, bubble point pressures of the system of methanol + methyl propionate were measured for several isopleths within temperature and pressure ranges of 382 to $444 \mathrm{~K}$ and 0.437 to $2.285 \mathrm{MPa}$, respectively. The vapor pressures of pure methanol and methyl propionate were also measured. The two-suffix Margules equation was used to represent the nonidealities of the liquid phase and the virial equation of state was used to take into account the nonidealities of the vapor phase. The temperature-dependent parameter of the two-suffix Margules equation was determined using Barker's method. The results show that the model can successfully estimate the bubble points of this system with average errors less than $0.69 \%$.

Keywords: Vapor-liquid equilibria; Raoult’s law; Margules equation; Saturation pressure.

\section{Introduction}

Methyl propionate is an ester which has a number of industrial applications; for example, it is used as a flavor or fragrance in the food or cosmetic industries, or as an intermediate in the chemical industry for producing other chemicals such as methyl methacrylate [1]. Methanol is one of the reactants which is used for producing methyl propionate along with ethylene and carbon monoxide, and therefore, for the design of a methyl propionate production plant, it is necessary to have accurate knowledge on the phase behavior of the constituents of the system. Polak and $\mathrm{Lu}$ [2] reported the isothermal vapor-liquid equilibria of the system of methanol + methyl propionate for one isotherm (298 K) within a low pressure range ranging from 11.5 to $19.78 \mathrm{kPa}$. Blanco and Ortega [3] have also reported the vapor-liquid equilibria of the system 
of methanol + methyl propionate for one isobar (0.141 MPa) within a temperature range of 345 to $361 \mathrm{~K}$. However, the investigated pressures and temperatures, which were studied by these groups, did not cover the complete range of industrial production pressures and temperatures. In this work, we have measured the vapor pressures of pure methanol and methyl propionate in the temperature ranges of 391.86 to $444.52 \mathrm{~K}$ and 402.94 to $444.51 \mathrm{~K}$, respectively, and the bubble point pressures of the binary mixtures of methanol + methyl propionate for several isopleths in the temperature range of 381.67 to $444.88 \mathrm{~K}$. In this way, new data within the industrial range of operational temperatures and pressures for producing methyl propionate is presented [4]. In addition, using the isothermal pressure-composition data obtained from our experimental data, we have determined, and presented, the activity coefficient parameter of the two-suffix Margules model for the binary system of methanol and methyl propionate.

\section{Experimental}

Methanol was purchased from J.T. Baker with a purity of over $99.8 \%$, and methyl propionate was obtained from Fluka with a purity of 99.8\%. Table 1 shows the purity and supplier information of these chemicals. The bubble point pressures of several samples with different compositions were measured at a number of temperatures using an equipment called the Cailletet apparatus. The equilibrium cell of the Cailletet apparatus is a glass tube with an inside diameter of 3 to $4 \mathrm{~mm}$. This tube is about $50 \mathrm{~cm}$ long and one end of the tube is closed. The sample with known composition is injected into the Cailletet tube from the open end and mercury is used to seal the tube and also to transmit pressure to the sample. A glass jacket is fixed around the equilibrium tube in order to circulate thermostat fluid around the sample to keep the temperature fixed at a certain desired value. Shariati and Peters [5] have extensively explained the Cailletet apparatus. 
For measuring the vapor pressures of pure methanol and pure methyl propionate, and also the bubble point pressures of binary mixtures of methanol + methyl propionate at several concentrations, visual measurements were performed for a sample with a fixed and known overall composition, the pressure was varied at a certain temperature until the last bubble of vapor disappeared. This pressure was recorded as the bubble point pressure of the mixture at that specific temperature [6].

In this work, silicone oil was used as the thermostat fluid. The bath temperature fluctuated no more than $0.04 \mathrm{~K}$. For temperature measurements, a platinum-resistance thermometer was used very close to the equilibrated sample. The accuracy of the temperature readings were $\pm 0.01 \mathrm{~K}$. The pressure was kept constant and measured using a dead weight gauge with an accuracy of $\pm 0.003 \mathrm{MPa}$. Shariati and Peters have previously explained the gas solubility measurements extensively [7].

\section{Modeling}

In this work, the gamma-phi formulation [8] was used to calculate the bubble point pressures. Such an approach should be used instead of the Raoult's law for systems whose vapor and liquid phases are considered to be nonideal. Including the fugacity coefficient in the formulation corrects for the vapor phase nonidealities, while the nonidealities in the liquid phase are taken into account by including the activity coefficient term. For the binary system of methanol + methyl propionate, the gamma-phi formulation becomes:

$P=\frac{x_{1} \gamma_{1} P_{1}^{\text {sat }} \varphi_{1}^{\text {sat }}}{\widehat{\varphi}_{1}}+\frac{x_{2} \gamma_{2} P_{2}^{\text {sat }} \varphi_{2}^{\text {sat }}}{\widehat{\varphi}_{2}}$

In Eq. (1), $P$ is the bubble point pressure, $x_{1}$ and $x_{2}$ are the mole fractions, $\gamma_{1}$ and $\gamma_{2}$ are the activity coefficients, $P_{1}^{\text {sat }}$ and $P_{2}^{\text {sat }}$ are the vapor pressures of methanol (1) and methyl propionate (2), respectively. In addition, $\varphi_{1}^{\text {sat }}$ and $\varphi_{2}^{\text {sat }}$ are the corresponding fugacity 
coefficients at the system temperature and the vapor pressures of the pure components, and $\hat{\varphi}_{1}$ and $\hat{\varphi}_{2}$ are the fugacity coefficients of components 1 and 2 in the mixture at the system temperature and pressure, respectively.

It is also possible to calculate the vapor phase compositions using the gamma-phi formulation, by the following equation:

$y_{1}=\frac{\chi_{1} \gamma_{1} P_{1}^{s a t} \varphi_{1}^{\text {sat }}}{P \widehat{\varphi}_{1}}$

and

$y_{2}=1-y_{1}$

The two-suffix Margules [9] model was selected for considering the nonidealities in the liquid phase:

$\frac{G^{E}}{R T}=A x_{1} x_{2}$

where, $G^{E}$ is the excess Gibbs energy and $A$ is the model parameter which is only a function of temperature. Using the excess Gibbs energy model of Eq. (4) and the definition of the partial properties, the activity coefficients of methanol and methyl propionate have the following relations, respectively, with composition and temperature:

$\ln \gamma_{1}=A x_{2}^{2}$

and

$\ln \gamma_{2}=A x_{1}^{2}$

The virial equation of state was used to determine $\varphi_{1}{ }^{\text {sat }}$ and $\varphi_{2}{ }^{\text {sat }}$ for the pure components, and $\hat{\varphi}_{1}$ and $\hat{\varphi}_{2}$ for components 1 and 2 in the mixture using the following equations:

$\ln \varphi_{1}^{\text {sat }}=\frac{B_{11} P_{1}^{\text {sat }}}{R T}$ 
$\ln \varphi_{2}^{\text {sat }}=\frac{B_{22} P_{2}^{s a t}}{R T}$

$\ln \hat{\varphi}_{1}=\frac{P}{R T}\left(B_{11}+y_{2}^{2} \delta_{12}\right)$

and

$\ln \hat{\varphi}_{2}=\frac{P}{R T}\left(B_{22}+y_{1}^{2} \delta_{12}\right)$

where

$\delta_{12}=2 B_{12}-B_{11}-B_{22}$

In the above equations, $B$ 's indicate the second virial coefficients which are determined by the approximation methods described in Ref. [8].

\section{Results and Discussion}

Table 2 presents the experimentally measured pressure-temperature $(P-T)$ data for the binary system of methanol + methyl propionate for eight different isopleths in the temperature and pressure ranges of 381.67 to $444.88 \mathrm{~K}$ and 0.437 to $2.285 \mathrm{MPa}$, respectively. The data at 0 and 1 in mole fraction are the vapor pressure data of pure methyl propionate and methanol, respectively, and the remaining data represent the bubble point curves of the binary mixture of methanol and methyl propionate at six different isopleths. Table 3 shows the parameters of the Antoine equation for methanol and methyl propionate, which were optimized based on the vapor pressure data of Table 2. It is clear from the pure-component data that methanol is more volatile than methyl propionate, with higher vapor pressures at each temperature. Fig. 1 shows the $P$-T data of this binary system graphically. The isopleths of Fig. 1 indicate that with increasing methanol mole fraction at constant temperature, the bubble point pressure of the system reaches a maximum and then marginally decreases. Fig. 2 shows this phenomenon on 
a $P-x$ diagram for the four isotherms of $410,420,430$, and $440 \mathrm{~K}$. These isothermal $P-\chi$ diagrams were determined by fitting polynomial functions to the experimental $P-T$ data at each composition. Each isotherm has a slight maximum at higher concentrations of methanol (at mole fractions close to 0.95 ), therefore, the system of methanol + methyl propionate has positive deviation from Raoult's law and because of such maximum points on the $P-x$ diagram, it should contain azeotropes. This issue has been confirmed by Blanco and Ortega [3], who experimentally determined the azeotropic point of methanol + methyl propionate for only the isobar of $141.3 \mathrm{kPa}$. Such a positive deviation from Raoult's law in this system indicates that the cohesive forces between like molecules are greater than the adhesive forces between unlike molecules, and the azeotrope shows the higher complexity of the system of methanol + methyl propionate.

The values of the A parameter of the two-suffix Margules model were determined by Barker's method, using VLE experimental data [9]. This method is iterative, because $y_{1}$ and $y_{2}$ can only be calculated after $A$ has been determined. Therefore, a successive substitution procedure must be used. In this method, for each isotherm, a value for the $A$ parameter was first assumed and the bubble point pressure for each selected liquid-phase composition was calculated using the modified Raoult's law. The error between the calculated and experimental bubble point pressures was determined for each composition at the constant temperature. Then, the value of the A parameter was optimized in order to minimize the calculated average error of the bubble point pressures. The objective function for the $A$ parameter optimization was as follows:

$O F=\operatorname{Min}\left\{\frac{1}{N} \sum_{i=1}^{N}\left|\frac{P_{b u b i}^{E x p}-P_{b u b i}^{C a l c}}{P_{b u b i}^{E x p}}\right|\right\}$

In Eq. (12), $\mathrm{N}$ is the number of data points at each isotherm. Immidiately, thereafter, $\mathrm{y}_{1}$ and $\mathrm{y}_{2}$ are computed from the first optimized value of the A parameter. The entire procedure should be repeated until the calculated values of $\mathrm{y}_{1}$ and $\mathrm{y}_{2}$ in two consecutive iterations are in 
agreement. Table 4 shows the optimized values of the $A$ parameter determined for this binary system at several temperatures. As can be seen from the values given in Table 4 , the $A$ parameter decreases with increasing temperature. This means that the nonidealities of this system decrease with increasing temperature. Fig. 3 shows the values of the $A$ parameter graphically. As can be seen, the $A$ parameter has a linear relation with temperature. By fitting a line on the values of $A$ parameter presented in Table 4, the following relation was determined between the $A$ parameter and temperature:

$A=-0.0053 * T / K+2.725$

Since the $A$ parameters had linear relations with temperature, their linear extrapolation is acceptable. In addition, in thermodynamics, the $A$ parameter of the two-suffix Margules equation is the calculated value of the activity coefficient at infinite dilution.

Using the optimized values of the A parameter and Eq. (1), the bubble point pressures were calculated. These bubble point pressures are compared with the experimental values in Fig. 4. As can be seen, the model was capable to calculate the bubble point pressures successfully with an average error of $0.69 \%$. It is also possible to determine the vapor composition using Eqs. (2) and (3). Fig. 5 shows the calculated liquid and vapor phase boundaries for the binary system of methanol + methyl propionate. As shown in Fig. 5, this model could successfully predict the azeotropic point of each isotherm.

\section{Conclusions}

The saturation pressures of the binary system of methanol + methyl propionate have been determined experimentally at different temperatures for several isopleths. From the 
experimental results, it can be concluded that this system has positive deviations from Raoult's law, to the extent that its $P-x$ diagram has a subtle maximum around a mole fraction of 0.95 . This means that this system has an azeotrope at that composition. The azeotrope was previously measured by Blanco and Ortega [3], but for only one low-pressure isobar. The system was modeled, using the gamma-phi formulation, and the results indicated this model is suitable for representing the phase behavior of this azeotropic system. 


\section{Acknowledgements}

Alireza Shariati would like to thank both Shiraz University and Eindhoven University of Technology for allowing him to collaborate in this research. 


\section{References}

[1] W. Clegg, G.R. Eastham, M.R.J. Elsegood, R.P. Tooze, X. L. Wang, K. Whiston, Highly Active and Selective Catalysts for the Production of Methyl Propanoate via the Methoxycarbonylation of Ethene, Chem. Commun., 18, 1877-1878 (1999).

[2] J. Polak, B.C.Y. Lu, Vapor-Liquid Equilibria of Methyl Propanoate + Methanol and Methyl Propanoate + Ethanol Systems at $25^{\circ} \mathrm{C}$, J. Chem. Eng. Data, 17, 456-458 (1972).

[3] A.M. Blanco, J. Ortega, Isobaric Vapor-Liquid Equilibria of Methanol + Methyl Ethanoate,

+ Methyl Propanoate, and + Methyl Butanoate at 141.3 kPa, J. Chem. Eng. Data, 41, 566-570 (1996).

[4] Ulmann’s Encyclopedia of Industrial Chemistry, Propionic Acid and Derivatives, WileyVCH, Weinheim (2014).

[5] A. Shariati, C.J. Peters, High-Pressure Phase Behavior of Systems with Ionic Liquids: Measurements and Modeling of the Binary System Fluoroform + 1-Ethyl-3Methylimidazolium Hexafluorophosphate, J. Supercritical Fluids 25, 109-117 (2003).

[6] A. Shariati, E.J.M. Straver, L.J. Florusse, C.J. Peters, Experimental Phase Behavior Study of a Five-Component Model Gas Condensate, Fluid Phase Equilibria, 362, 147-150 (2014).

[7] A. Shariati, C.J. Peters, Measurements and Modeling of the Phase Behavior of Ternary Systems of Interest for the GAS Process: I. The System Carbon Dioxide+1Propanol+Salicylic Acid, J. Supercritical Fluids, 23, 195-208 (2002).

[8] J.M. Smith, H. Van Ness, M. Abbott, Introduction to Chemical Engineering Thermodynamics, McGraw-Hill, Seventh Edition, 2005.

[9] J.M. Prausnitz, R.N. Lichtenthaler, E. Gomes de Azevedo, Molecular Thermodynamics of Fluid-Phase Equilibria, Prentice Hall, Third Edition, 1999. 


\section{Figures Captions}

Fig. 1. P-T diagram of the binary system of methanol (1) + methyl propionate (2) at several isopleths.

Fig. 2. P- $x$ diagram of the binary system of methanol + methyl propionate (2) at different isotherms.

Fig. 3. Temperature dependency of the $A$ parameter.

Fig. 4. Comparison between experimental and calculated bubble point pressures at different isotherms.

Fig. 5. Calculated bubble point and dew point curves for he binary system of methanol (1) + methyl propionate (2) using the gamma-phi formulation. 
Table 1. The suppliers and purities of the chemicals.

\begin{tabular}{|l|l|l|}
\hline Chemical & Supplier & Purity, \% \\
\hline Methanol & J.T. Baker & 99.8 \\
\hline Methyl Propionate & Fluka & 99.8 \\
\hline
\end{tabular}


Table 2. Experimental pressure-temperature $(P-T)$ data of the binary system of methanol $(1)+$ methyl propionate (2) for the different isopleths.

\begin{tabular}{|c|c|c|c|}
\hline \multicolumn{4}{|c|}{$\mathrm{x}_{1}=0.0000$} \\
\hline $\mathrm{T} / \mathrm{K}$ & $\mathrm{P} / \mathrm{MPa}$ & $T / K$ & $\mathrm{P} / \mathrm{MPa}$ \\
\hline 402.94 & 0.437 & 423.61 & 0.698 \\
\hline 408.11 & 0.495 & 433.97 & 0.863 \\
\hline 413.27 & 0.555 & 444.51 & 1.064 \\
\hline 418.68 & 0.628 & & \\
\hline \multicolumn{4}{|c|}{$\mathrm{x}_{1}=0.1648$} \\
\hline $\mathrm{T} / \mathrm{K}$ & $\mathrm{P} / \mathrm{MPa}$ & $\mathrm{T} / \mathrm{K}$ & $\mathrm{P} / \mathrm{MPa}$ \\
\hline 392.62 & 0.457 & 423.74 & 0.928 \\
\hline 397.61 & 0.517 & 434.27 & 1.149 \\
\hline 402.75 & 0.585 & 444.60 & 1.402 \\
\hline 413.19 & 0.740 & & \\
\hline \multicolumn{4}{|c|}{$x_{1}=0.2927$} \\
\hline $\mathrm{T} / \mathrm{K}$ & $\mathrm{P} / \mathrm{MPa}$ & $\mathrm{T} / \mathrm{K}$ & $\mathrm{P} / \mathrm{MPa}$ \\
\hline 387.47 & 0.457 & 423.88 & 1.073 \\
\hline 392.59 & 0.522 & 434.14 & 1.328 \\
\hline 402.81 & 0.670 & 444.76 & 1.631 \\
\hline 413.73 & 0.862 & & \\
\hline
\end{tabular}


Table

2.

\begin{tabular}{|c|c|c|c|}
\hline \multicolumn{4}{|c|}{$\mathrm{x}_{1}=0.5047$} \\
\hline $\mathrm{T} / \mathrm{K}$ & $\mathrm{P} / \mathrm{MPa}$ & $\mathrm{T} / \mathrm{K}$ & $\mathrm{P} / \mathrm{MPa}$ \\
\hline 382.41 & 0.449 & 423.89 & 1.251 \\
\hline 392.95 & 0.597 & 434.29 & 1.551 \\
\hline 402.88 & 0.767 & 444.69 & 1.929 \\
\hline 413.69 & 0.993 & & \\
\hline \multicolumn{4}{|c|}{$\mathrm{x}_{1}=0.6988$} \\
\hline $\mathrm{T} / \mathrm{K}$ & $\mathrm{P} / \mathrm{MPa}$ & $\mathrm{T} / \mathrm{K}$ & $\mathrm{P} / \mathrm{MPa}$ \\
\hline 382.15 & 0.475 & 424.14 & 1.369 \\
\hline 392.69 & 0.633 & 434.62 & 1.727 \\
\hline 403.08 & 0.831 & 444.77 & 2.133 \\
\hline 413.82 & 1.079 & & \\
\hline \multicolumn{4}{|c|}{$\mathrm{x}_{1}=0.8571$} \\
\hline $\mathrm{T} / \mathrm{K}$ & $\mathrm{P} / \mathrm{MPa}$ & $\mathrm{T} / \mathrm{K}$ & $\mathrm{P} / \mathrm{MPa}$ \\
\hline 381.67 & 0.475 & 423.27 & 1.394 \\
\hline 391.99 & 0.635 & 433.72 & 1.767 \\
\hline 402.36 & 0.836 & 444.13 & 2.228 \\
\hline 412.76 & 1.087 & & \\
\hline
\end{tabular}

Continued. 
Table

2.

\begin{tabular}{|c|c|c|c|}
\hline \multicolumn{4}{|c|}{$\mathrm{x}_{1}=0.9547$} \\
\hline $\mathrm{T} / \mathrm{K}$ & $\mathrm{P} / \mathrm{MPa}$ & $\mathrm{T} / \mathrm{K}$ & $\mathrm{P} / \mathrm{MPa}$ \\
\hline 382.39 & 0.480 & 424.22 & 1.436 \\
\hline 392.68 & 0.640 & 434.70 & 1.827 \\
\hline 402.95 & 0.845 & 444.88 & 2.285 \\
\hline 413.50 & 1.109 & & \\
\hline \multicolumn{4}{|c|}{$\mathrm{x}_{1}=1.0000$} \\
\hline $\mathrm{T} / \mathrm{K}$ & $\mathrm{P} / \mathrm{MPa}$ & $\mathrm{T} / \mathrm{K}$ & $\mathrm{P} / \mathrm{MPa}$ \\
\hline 391.86 & 0.619 & 423.45 & 1.407 \\
\hline 402.26 & 0.824 & 434.11 & 1.802 \\
\hline 413.05 & 1.089 & 444.52 & 2.270 \\
\hline
\end{tabular}

$\mathrm{u}(\mathrm{T})=0.04 \mathrm{~K}, \mathrm{u}(\mathrm{P})=0.003 \mathrm{MPa}, \mathrm{u}(\mathrm{x})=0.0050$

Continued. 
Table 3. The optimized parameters of the Antoine equation for methanol and methyl propionate.

\begin{tabular}{|c|c|c|c|c|}
\hline Name & Temperature range & A & B & C \\
\hline Methanol & $391.86-444.52$ & 9.921 & 3838 & -22.86 \\
\hline Methyl propionate & $402.94-444.51$ & 7.734 & 3075 & -43.72 \\
\hline
\end{tabular}

$$
\ln P^{s a t} / M P a=A-\frac{B}{T / K+C}
$$


Table 4. Values of the A parameter as a function of temperature.

\begin{tabular}{|c|c|}
\hline $\mathrm{T} / \mathrm{K}$ & $\mathrm{A}$ \\
\hline 410 & 0.55 \\
\hline 420 & 0.50 \\
\hline 430 & 0.45 \\
\hline 440 & 0.39 \\
\hline
\end{tabular}




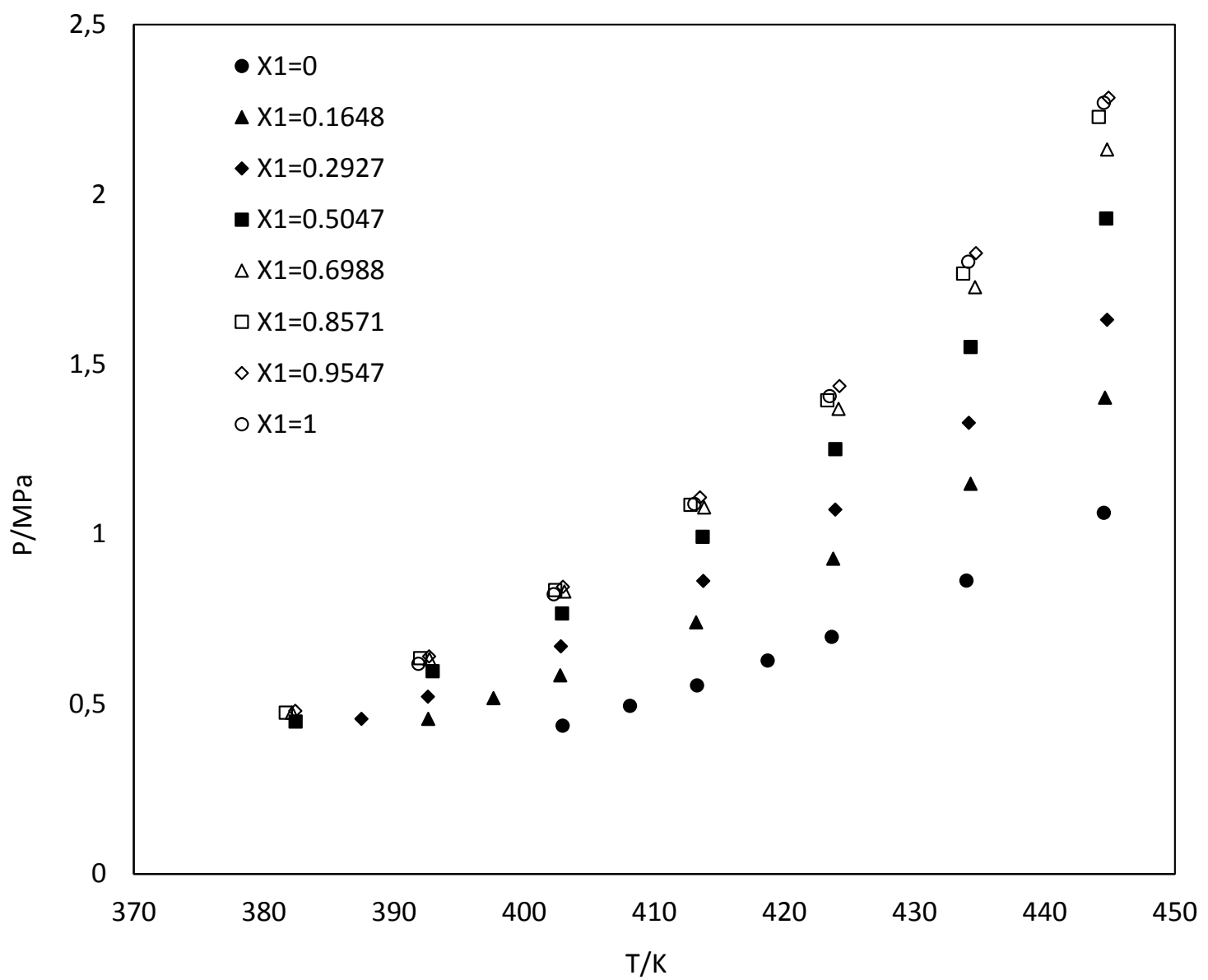

Fig. 1. P-T diagram of the binary system of methanol (1) + methyl propionate (2) at several isopleths. 


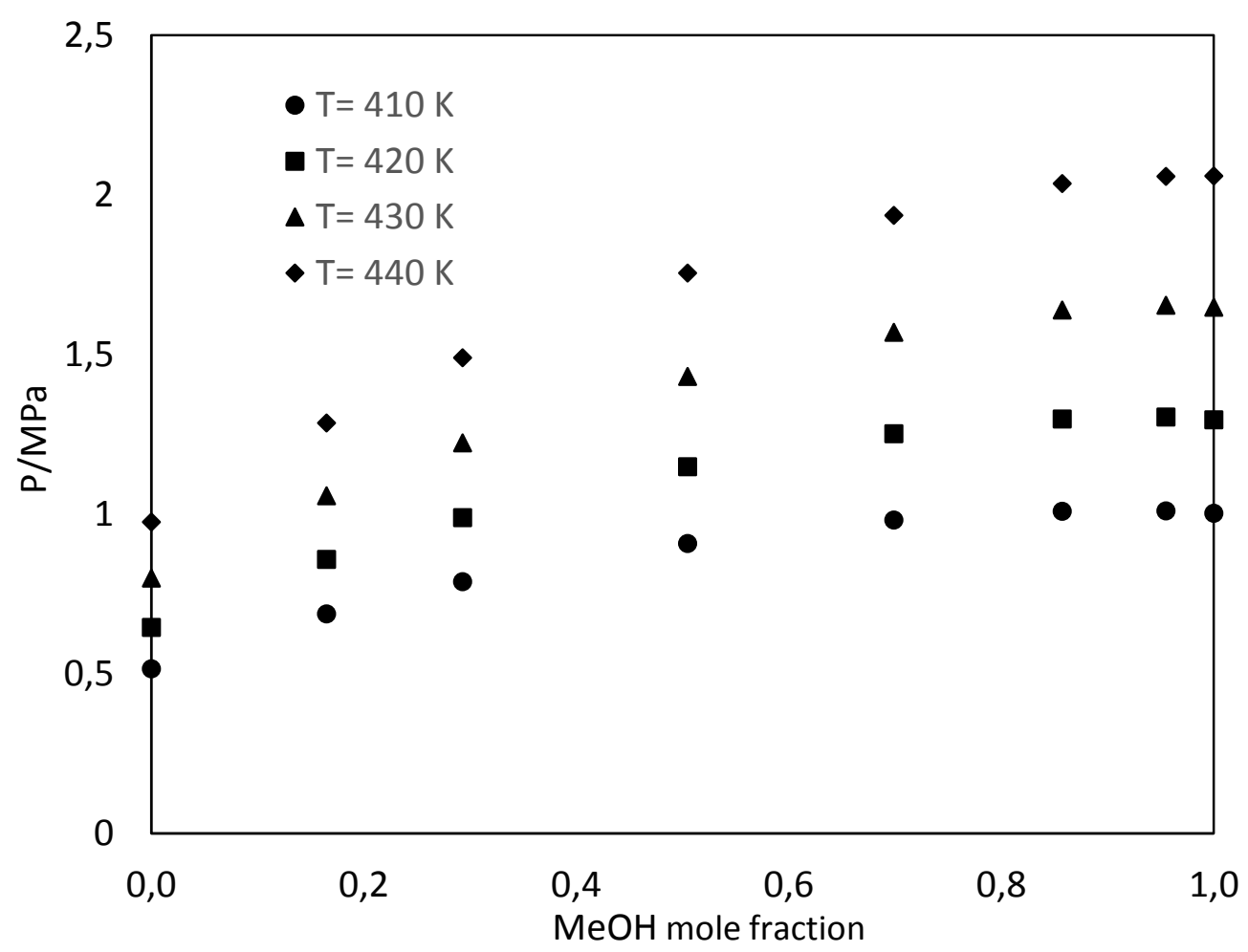

Fig. 2. $P-x$ diagram of the binary system of methanol + methyl propionate (2) at different isotherms. 


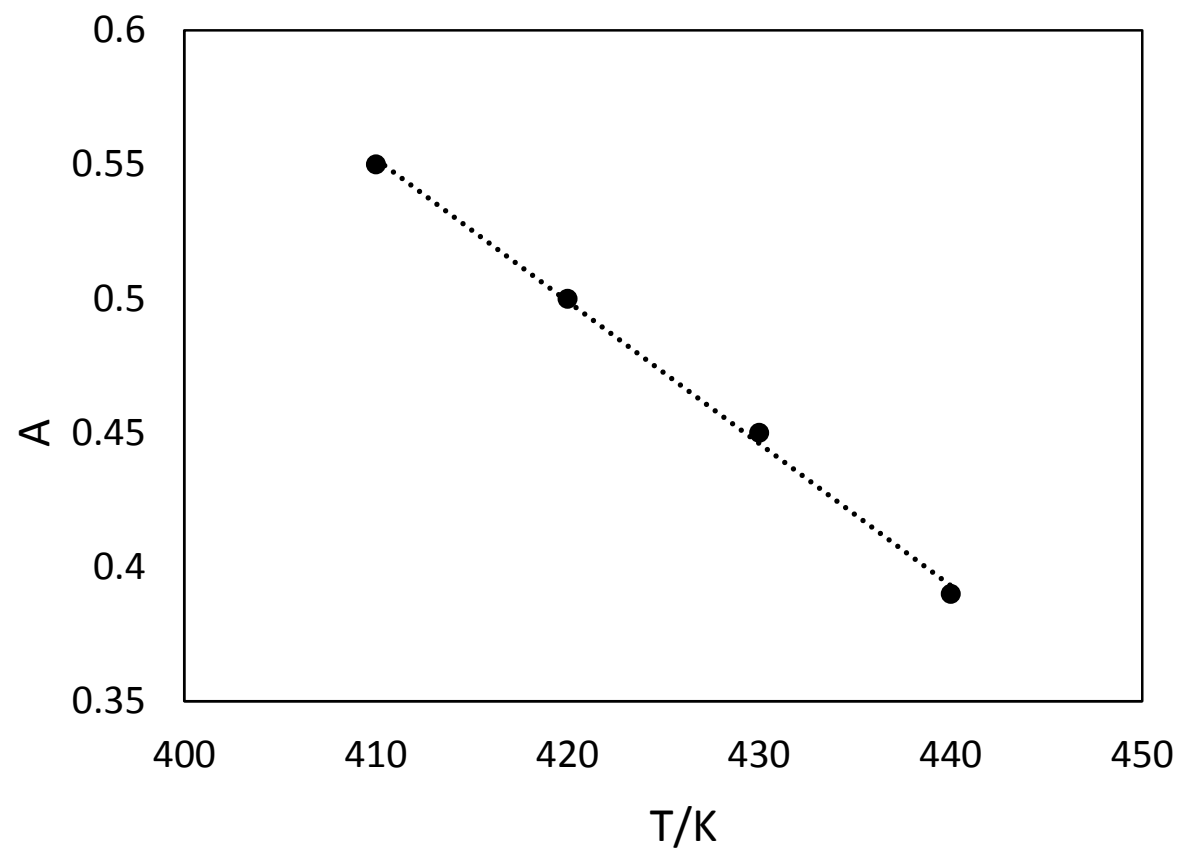

Fig. 3. Temperature dependency of the $A$ parameter. 


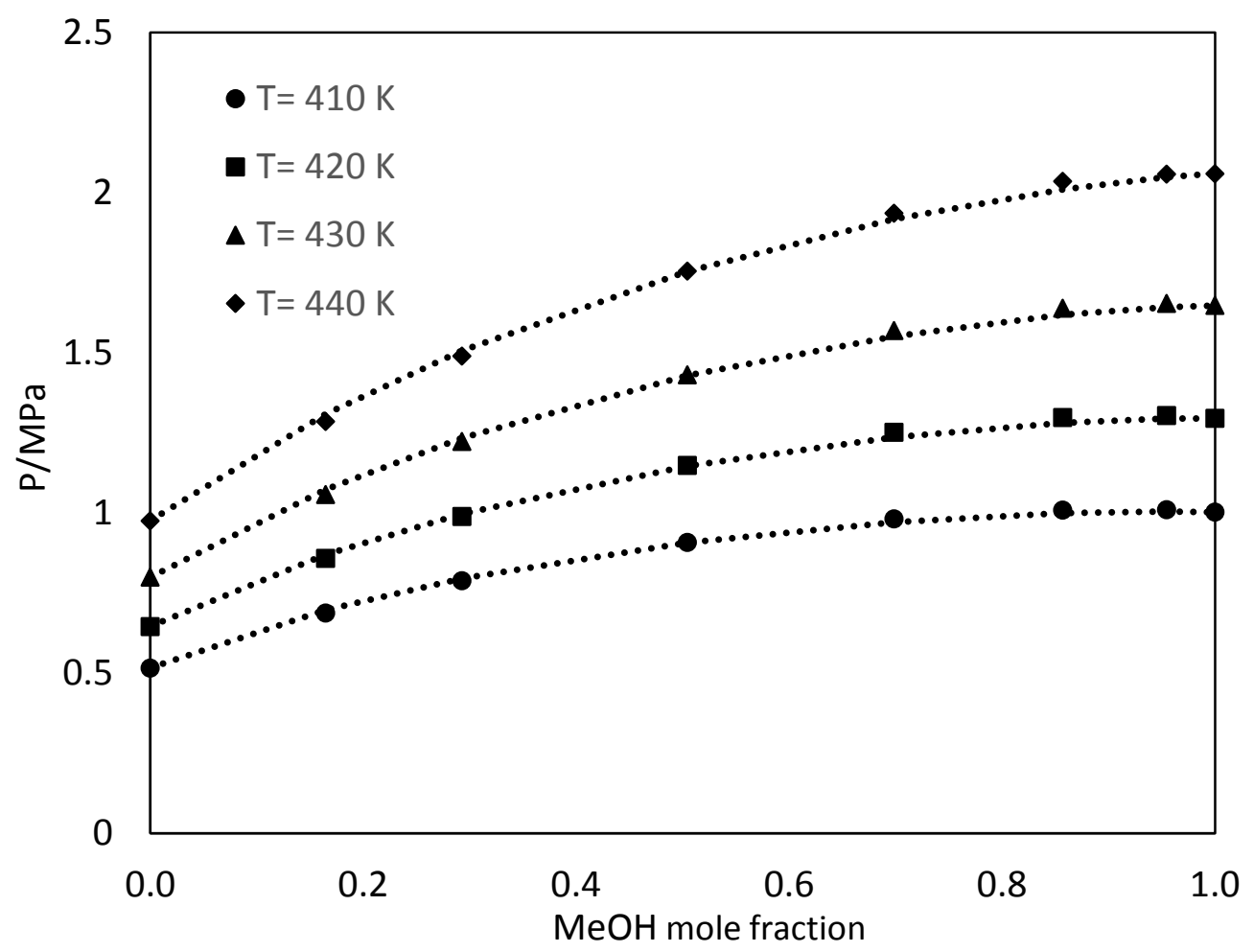

Fig. 4. Comparison between experimental and calculated bubble point pressures at different isotherms. 


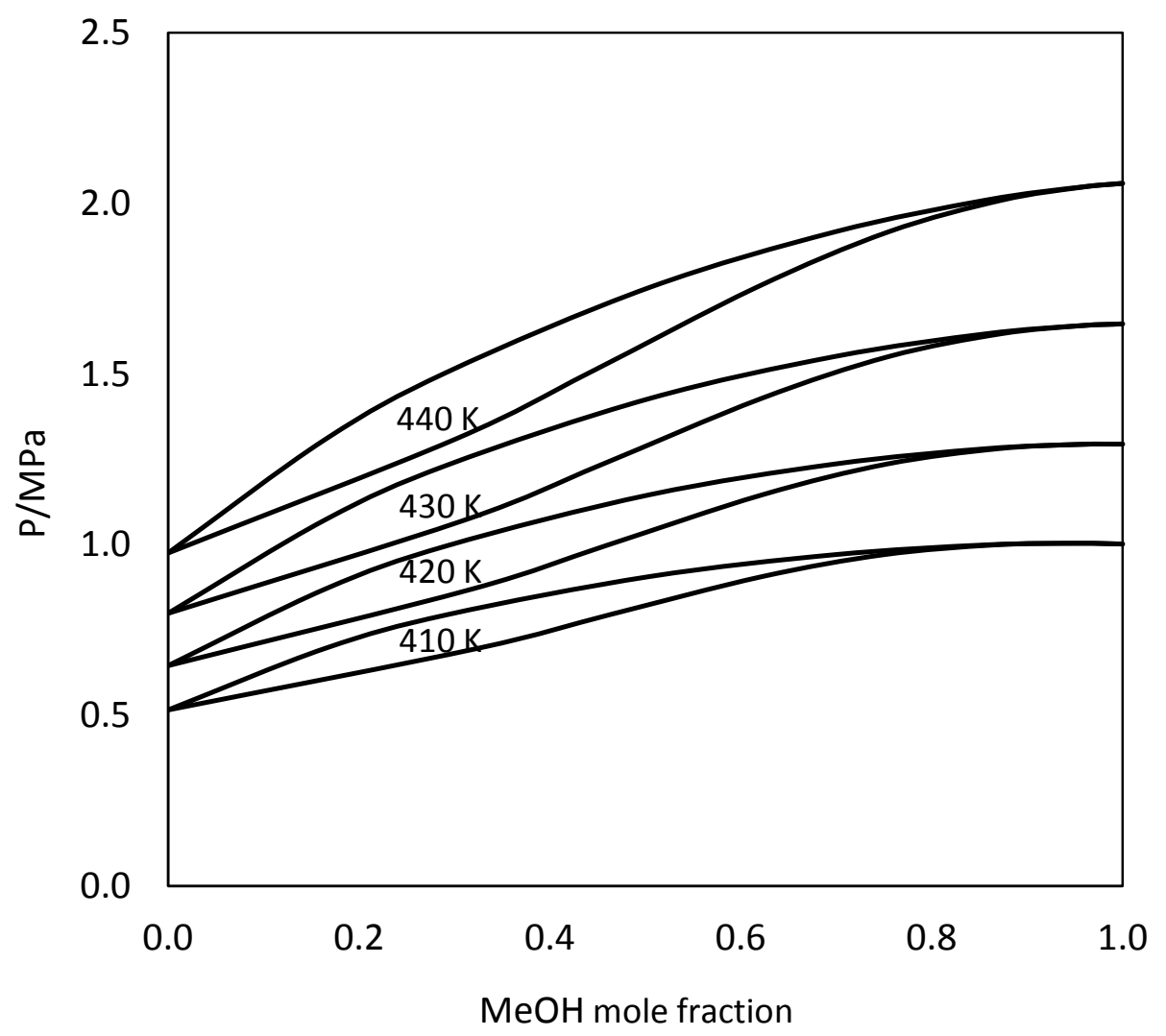

Fig. 5. Calculated bubble point and dew point curves for the binary system of methanol (1) + methyl propionate (2) using the gamma-phi formulation. 